\title{
Statistical model of variable allometric growth: otolith growth in Micropogonias furnieri (Actinopterygii, Sciaenidae)
}

\author{
G. Bervian*, N. F. Fontoura*† and M. Haimovici* \\ * Faculdade de Biociências; Pontifícia Universidade Católica do Rio Grande do Sul \\ (PUCRS), Av. Ipiranga, 6681, P. O. Box. 1429, 90619-900, Porto Alegre, RS, \\ Brazil and \$Departamento de Oceanografia, Universidade Federal do Rio Grande, \\ P. O. Box 474, 96201-900, Rio Grande, RS, Brazil
}

(Received 25 October 2004, Accepted 27 June 2005)

\begin{abstract}
The main objective of this study was to develop a statistical model for accurate estimates of relative growth. The method was based on identifying patterns of the residuals obtained from the Huxley's allometric equation. Three different approaches were applied: (1) growth with variable proportionality and constant allometry coefficient, (2) growth with constant proportionality and variable allometry coefficient and (3) distinct growth phases in which proportionality and allometry coefficients remained constant. The proposed statistical models were applied to the relationship of the otolith size and fish size of whitemouth croaker Micropogonias furnieri. The best fit was obtained when using approach (3). A change in the growth parameters was associated with the attainment of sexual maturity.

(C) 2006 The Fisheries Society of the British Isles
\end{abstract}

Key words: Micropogonias furnieri; otolith; relative growth; statistical models; variable allometric growth.

\section{INTRODUCTION}

The power-function model $\left(y=a x^{b}\right)$, originally proposed by Huxley (1924) for the description of allometric growth (variation in form related to variation in size) has been conventionally used in studies of animal growth. According to this equation, body dimensions increase relative to each other according to a constant defined as $b$, the allometric coefficient. When $b>1$, the $y$ structure is growing relatively faster than the $x$ structure, and allometry is positive. When $b<1$, allometry is negative. The case in which $b=1$ is known as isometry and implies that $y$ and $x$ are proportional to each other. The $a$ parameter is the proportionality coefficient between the two variables and corresponds to the value of $y$ when $x=1$ (White \& Gould, 1965).

$\dagger$ Author to whom correspondence should be addressed. Tel.: +55 5133203500 ext. 4146; fax: +55 513320 3568; email: nfontoura@pucrs.br 
Huxley's (1924) model is frequently used for description of relative growth and determination of sexual maturity in crustaceans, fish length estimates through backcalculation from scales and otoliths and for the statistical description of the relationship between mass and length (Le Cren, 1951; Hartnoll, 1978; Francis, 1990).

The condition factor is generally determined through the power-function model, considering the $a$ parameter as constant $\left(a=y x^{-b}\right)$. This parameter is important for the comparison of populations living in specific food and climatic conditions, the identification of reproductive cycles, and also for the follow-up of the feeding activity of a species, evaluating the efficiency of the use of food sources (Weatherley, 1972; Ricker, 1975).

Although frequently used, the Huxley (1924) model has shown limited capacity for the adequate description of relative growth as $b$, assumed to be constant, may change during the life cycle (Lovett \& Felder, 1989).

The study of calcareous structures such as otoliths, scales and opercular bones has been important for the determination of the relationship between length and age in fishes, through backcalculation (Casselman, 1990; Francis, 1990). Estimations of length based on annuli spacing, however, can result in significant error if the mathematical model employed is not appropriate for the description of the allometric variation of the structures throughout ontogeny (Campana, 1990; Zivkov, 1996).

Micropogonias furnieri (Desmarest) is a marine demersal species, which has a wide distribution along the Atlantic coast, from Mexico to Argentina (Isaac, 1988). Movements into estuaries are related to its life cycle. Young individuals use these areas for feeding and growth, returning to the ocean when adults, although some individuals may remain inside an estuary throughout their whole life cycle (Vazzoler, 1991). Total length $\left(L_{\mathrm{T}}\right)$ at first maturation $\left(L_{\mathrm{T} 50}\right)$ was estimated at $200 \mathrm{~mm}$ for the estuarine resident group (Castello, 1986; Vizziano et al., 2002) and $330-350 \mathrm{~mm}$ for the those that migrate as juveniles to the adjacent coastal waters and mature at a higher age in marine waters (Vazzoler, 1971). The large size at maturity and large otoliths makes this species particularly suitable for allometric studies of its growth pattern. Volpedo \& Echeverría (2003) classified the ecomorphological pattern of the sagitta of several species of the Argentine continental shelf, grouping M. furnieri with other bottom-related species.

This work investigated a mathematical model for a more accurate description of relative growth, by considering ontogenetic variation of growth parameters and using M. furnieri as a model species.

\section{HYPOTHESES FOR CONSTRUCTING THE MODEL}

The hypotheses for creating a mathematical model were based on the analysis of the distribution of residuals after applying Huxley's allometric equation (Huxley, 1924). As shown in Fig. 1, a random distribution of residuals after adjusting the Huxley regression model suggests that the equation is adequate and that the relative growth is well described. If there is no random distribution of residuals the model is not adequate, and more complex equations are necessary for a better description of relative growth. In this case, development of the 


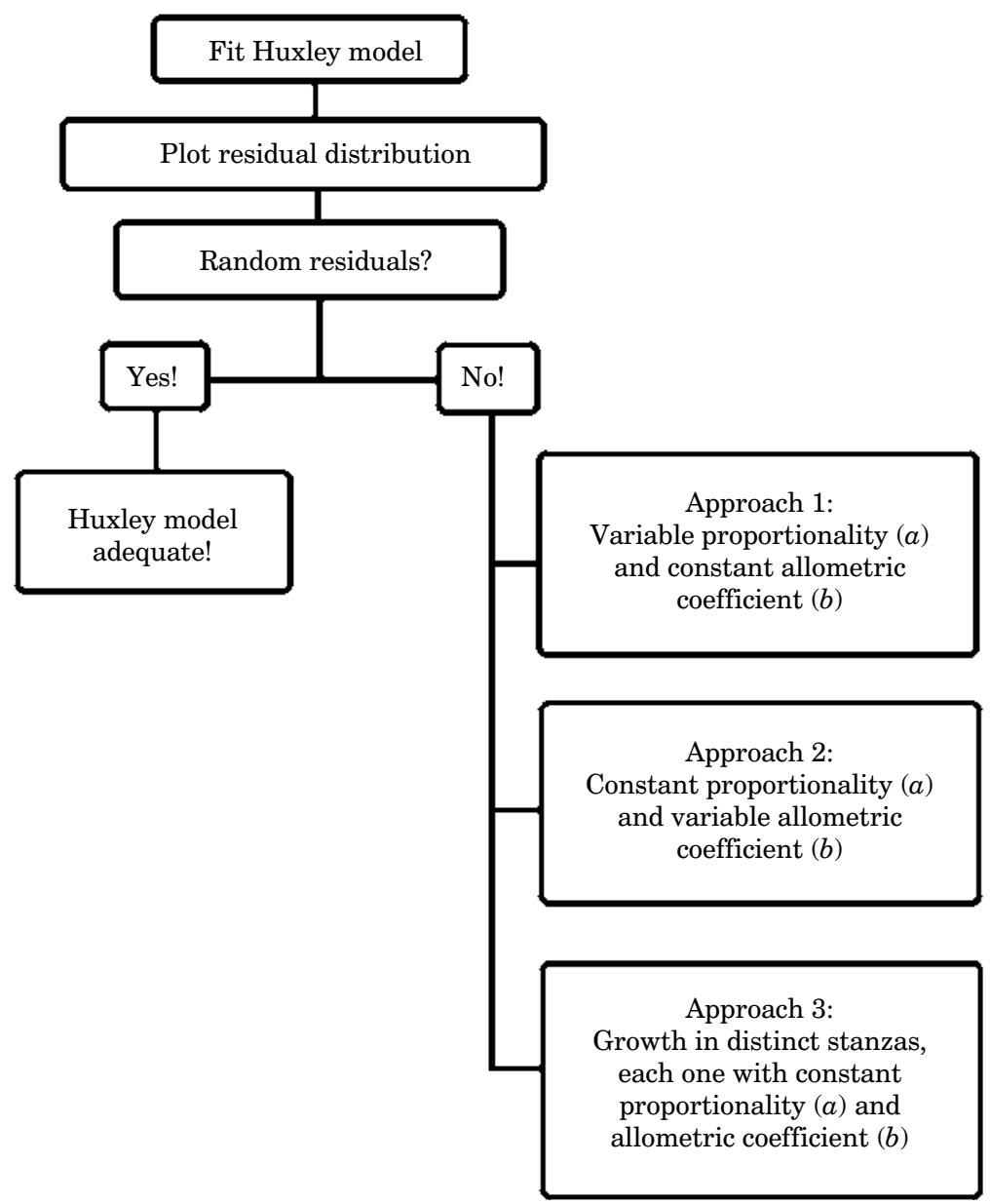

FIG. 1. Methodological approach for improving the general model of relative growth of Huxley (1924), considering complex allometric patterns.

equations is based on the interpretation of the behaviour of parameters $a$ and $b$ of Huxley's equation, using three different approaches described in Fig. 1.

\section{APPROACH 1: VARIABLE PROPORTIONALITY AND CONSTANT ALLOMETRY}

Approach 1 transfers all the unexplained variability to the proportionality coefficient $(a)$, considering parameter $b$ as constant and parameter $a$ as a function of $x: y=f(x) x^{b}$. From the fishery point of view, this approach is not relevant, since variation of parameter $a$ as a function of $x$ has no biological meaning (White \& Gould, 1965). On the other hand, keeping parameter $a$ constant is important proceeding since it is generally used as an indicative of the condition factor (Le Cren, 1951). Approach 1 was therefore abandoned. 


\section{APPROACH 2: CONSTANT PROPORTIONALITY AND COMPLEX ALLOMETRY}

Several authors have applied different approaches (Strauss, 1993) with complex allometry patterns. In this approach, all the variability is transferred to $b$, considering parameter $a$ constant and parameter $b$ as a function of $x[b=f(x)]$ : $y=a x^{f(x)}$. This approach is convenient since the distribution of $b$ values as a function of variable $x$, besides representing the relative growth rates between variables $x$ and $y$, is also indicative of the animal's growth pattern. This pattern can be: (1) constant isometric, characterized by the random distribution of $b$ along a horizontal line where $f(x)=1$ (Fig. 2, A), (2) constant allometric, characterized by the random distribution of $b$ along a horizontal line where $f(x)=$ any constant different from 1 (Fig. 2, B), or (3) variable allometric, in which the distribution of $b$ follows a pattern different from that of a horizontal line, where $f(x)=$ any mathematical function (Fig. 2, C).

\section{APPROACH 3: GROWTH IN DISTINCT STANZAS, EACH ONE WITH CONSTANT A AND B}

Approach 3 considers a growth pattern with different phases or stanzas, separated by a stanza changing point (SCP), which indicates the value of $x$ at the moment when the animal growth pattern changes. Huxley (1924) already identified the presence of different growth phases. Strauss (1993) calls this approach as polyphasic allometry. For simplicity, a model with only two stanzas will be described, although the general model accepts the use of several stanzas.

Each growth phase is described through different power equations, one for animals with a size smaller than the SCP and another for animals larger than the SCP: stanza $1, y_{1}=a_{1}(x)^{b_{1}}$ and stanza $2, y_{2}=a_{2}(x)^{b_{2}}$ where $a_{1}$ and $b_{1}$ are the

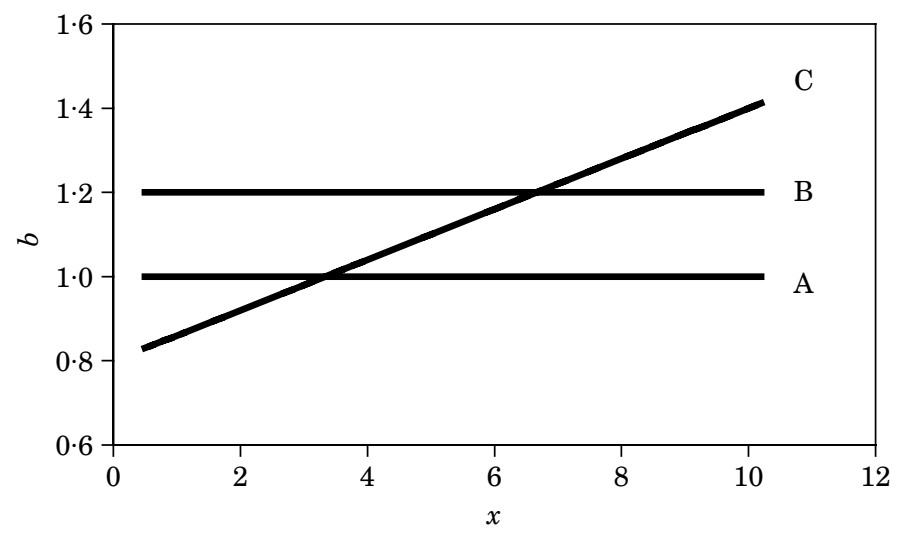

FIG. 2. Patterns of animal growth indicated by distribution of allometry coefficient $(b)$ against $x$. A, Constant isometric growth $(b=1)$; $\mathrm{B}$, constant allometric growth $(b<$ or $>1)$; C, variable allometric growth $[b=f(x)]$. 
parameters of the allometric equation of stanza 1 , and $a_{2}$ and $b_{2}$ are the parameters of the allometric equation of stanza 2 .

The polyphasic growth pattern can be mathematically described by two different procedures, which are described below.

\section{POWER-EQUATIONS SWITCHED ON AND OFF BY A LOGISTIC FUNCTION: APPROACH $3 \mathrm{~A}$}

This approach integrates stanzas 1 and 2 equations into a single mathematical function by the introduction of an empirical logistical equation acting as a switch function $\left(F_{\mathrm{w}}\right)$. By multiplying any function by a logistic $\left(F_{\mathrm{w}}\right)$, the function could be turned on, when $F_{\mathrm{w}}$ value is near one, or off, when $F_{\mathrm{w}}$ value is near zero: $F_{\mathrm{W}}=\left[1+\mathrm{e}^{R_{\mathrm{sc}}\left(x-P_{\mathrm{sc}}\right)}\right]^{-1}$, where $R_{\mathrm{sc}}$ is the stanza changing rate and $P_{\mathrm{sc}}$ is the value of the variable $x$ that corresponds to the SCP.

Using a logistic function as a switch is an interesting tool because the function can generate $y$ values that change from zero to one or from one to zero with any $x$ values. The $P_{\mathrm{sc}}$ indicates the average midpoint from where the growth pattern is changing and the $R_{\mathrm{sc}}$ controls how fast the change occurs. Using a set of logistic functions as switches, complex patterns could be described by a single equation. For two stanzas, the resulting mathematical function is as follows:

$$
y=\left[\left(a_{1} x^{b_{1}}\right) F_{\mathrm{w}}\right]+\left[\left(a_{2} x^{b_{2}}\right)\left(1-F_{\mathrm{w}}\right)\right] .
$$

POWER-EQUATION WITH $a$ AND $b$ PARAMETERS SWITCHED INTO DIFFERENT VALUES BY LOGISTIC FUNCTIONS: APPROACH $3 \mathrm{~B}$

This approach considers the power-function as a general growth rule where parameters $a$ and $b$ could be modified together to specific values for each stanza, regulated by ontogenetic or environmental factors (Swain \& Foote, 1999). A growth pattern with a polyphasic allometry with three or more stanzas could be described by this approach, but at the cost of increased mathematical complexity, with a switch function for each additional stanza necessary. To keep the model simple, only two states will be considered $\left(a_{1}\right.$ and $a_{2} ; b_{1}$ and $\left.b_{2}\right)$, before and after the SCP, following a logistic function:

$$
y=f(a) x^{f(b)}
$$

where $\quad f(a)=a_{1}+\left(a_{2}-a_{1}\right)\left[1+\mathrm{e}^{R_{\mathrm{sc}}\left(x-P_{\mathrm{sc}}\right)}\right]^{-1}, \quad f(b)=b_{1}+\left(b_{2}-b_{1}\right)$ $\left[1+\mathrm{e}^{R_{\mathrm{sc}}\left(x-P_{\mathrm{sc}}\right)}\right]^{-1}$, and $a_{1}$ and $a_{2}$ are values of $a$ in the first and second stanzas, and $b_{1}$ and $b_{2}$ are values of $b$ in the first and second stanzas, respectively.

\section{MATERIALS AND METHODS}

\section{RELATIONSHIP BETWEEN OTOLITH LENGTH AND TOTAL LENGTH OF M. FURNIERI}

The relationship between otolith length $\left(L_{\mathrm{OT}}\right)$ and $L_{\mathrm{T}}$ in $M$. furnieri was used as an example to analyse the behaviour of the allometric coefficient. The data used in this analysis are derived from samples collected on Rio Grande do Sul coast, between 1987 
and 1992, comprising a total of 1321 specimens of $M$. furnieri. Using the empirical function for backcalculation, $L_{\mathrm{OT}}$ was established as the predictor variable:

$$
L_{\mathrm{T}}=a L_{\mathrm{OT}}^{b}
$$

Parameters $a$ and $b$ of equation (3) were estimated by the least squares from lntransformed data:

$$
\ln L_{\mathrm{T}}=\ln a+b \ln L_{\mathrm{OT}}
$$

To minimize the effects of data concentration in particular size classes, as well as decreasing the error of $\ln$-transformation resulting from natural variability (Smith, 1993), data were grouped into $L_{\mathrm{T}}$ class intervals of $1 \mathrm{~mm}$, and the average $L_{\mathrm{OT}}$ were calculated for each size class. The dispersion of individual data, however, was not omitted.

Knowing $a$, an allometric coefficient for each size class $\left(b_{\mathrm{sc}}\right)$ was isolated through the following expression, derived from equation (4):

$$
b_{\mathrm{sc}}=\ln \left(L_{\mathrm{T}} a^{-1}\right)\left(\ln L_{\mathrm{OT}}\right)^{-1}
$$

To identify the presence of any pattern, each value of $b_{\mathrm{sc}}$ was plotted as a function of $L_{\mathrm{OT}}$. Once a non-linear pattern was identified, it was empirically described through a polynomial equation of the minimum degree that adequately fitted the data. Polynomial adjustment was performed using Microsoft Excel 5.0:

$$
b_{\mathrm{sc}}=c_{n} L_{\mathrm{OT}}{ }^{n}+c_{n-1} L_{\mathrm{OT}}{ }^{n-1}+\ldots+c_{1} L_{\mathrm{OT}}+c_{0}
$$

where $c$ represents the parameters of the polynomial equation.

Polynomial models can be useful to express complex relationships, as in variation in the allometric coefficient, but the method is solely empirical, making almost impossible any biological interpretation of the parameters (Needham, 1950; Gould, 1966). Nevertheless, polynomials are simple to use and fit, and could be used as empirical functions describing the allometric coefficient $\left(b_{\mathrm{sc}}\right)$ for approach 2:

$$
y=a x^{\left(c_{n} L_{\mathrm{OT}}{ }^{n}+c_{n-1} L_{\mathrm{OT}}{ }^{n-1}+\ldots+c_{1} L_{\mathrm{OT}}+c_{0}\right)} .
$$

As a by-product, the polynomial model works as a tool to identify changes in the allometric coefficient throughout ontogenetic development. By definition, a derivative equation describes the pattern of how the instantaneous rates $(\mathrm{d} y / \mathrm{d} x)$ of any function are changing through a range of $x$ values. By using the first order derivative of the polynomial equation (6), the $P_{\mathrm{sc}}$, necessary for approach 3, could be identified as the $x$ value where the function crosses the $x$-axis. More than just theoretical information, the $P_{\mathrm{sc}}$ is indicative of different growth phases and represents important information to be used in model development.

Once the $P_{\mathrm{sc}}$ is identified, independent power equations could be adjusted to data below and above this point (approach 3): $y_{1}=a_{1}(x)^{b_{1}} ; y_{2}=a_{2}(x)^{b_{2}}$. Equations (1) (approach 3a) and (2) (approach 3b) were then adjusted using previous estimates of $a_{1}$, $b_{1}, a_{2}, b_{2}$ and $P_{\mathrm{sc}}$ as starting values. The $R_{\mathrm{sc}}$ was initiated as one as the starting value. Model fitting was performed by SPSS 11.5 Non-linear Regression Routine, using least squares as loss function, Sequential Quadratic Programming as estimation method and bootstrap estimates of s.E. At this point, as ln-transformation was not necessary, model adjustment was performed using all individual data.

After fitting the solutions (equations) describing growth pattern with complex or polyphasic allometry, each one following a different approach, the problem was which solution to choose. The criteria could be: (1) just numerical (or statistical), by minimizing the residual variance $\left(S^{2}\right)$ for measuring the fitness or maximizing the coefficient of determination $\left(r^{2}\right)$ for measuring the relationship, (2) visual, with no identifiable pattern in residual distribution, (3) by parsimony, choosing the model with least parameters, or (4) theoretical, selecting the model in which the parameters or most of them present biological meaning. To decide which model to use based in all these criteria goes beyond the scope of the present work. 


\section{RESULTS}

The relationship between $L_{\mathrm{OT}}$ and $L_{\mathrm{T}}$ for $M$. furnieri was described as follows [Fig. 3(a)]: $L_{\mathrm{T}}=19 \cdot 9 L_{\mathrm{OT}}^{1.061}\left(S^{2}=767 \cdot 4\right)$. The Huxley (1924) equation did not fit the distribution of mean $L_{\mathrm{T}}$ and $L_{\mathrm{OT}}$ points. The non-random pattern of the standardized residuals [Fig. 3(b)] shows the inadequacy of the simple power-function. Further, the allometric coefficient $\left(b_{\mathrm{sc}}\right)$ for each otolith length class was isolated (equation 5). Instead of presenting a linear horizontal distribution, the allometric coefficient varied as a function of size, presenting a complex pattern. To this pattern a polynomial function of the third degree was fitted [Fig. 3(c)]: $b_{\mathrm{sc}}=0 \cdot 00003011 L_{\mathrm{OT}_{m}}^{3}-0 \cdot 001950 L_{\mathrm{OT}_{m}^{2}}^{2}+0 \cdot 03685 L_{\mathrm{OT} m}+0 \cdot 8756\left(r^{2}=0 \cdot 937\right)$, where $m$ is the mean. This polynomial function can be used as a substitute for the

(a)

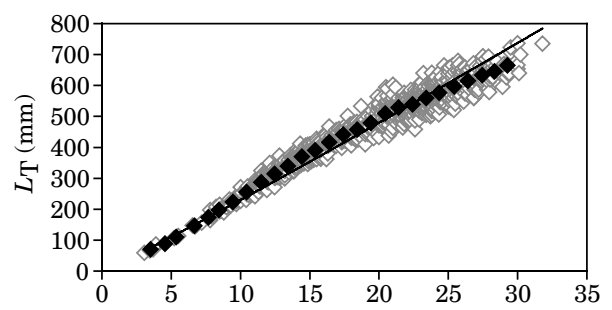

(c)

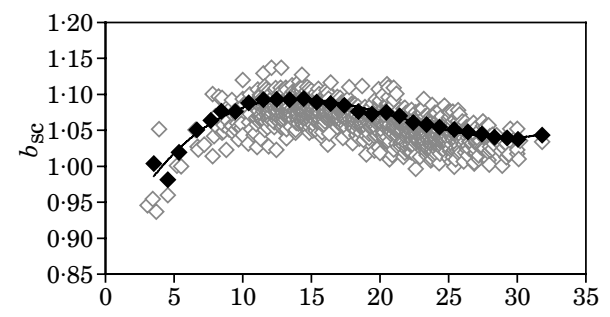

(e)

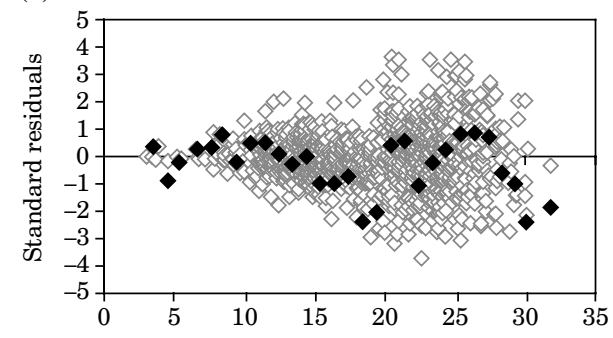

(b)

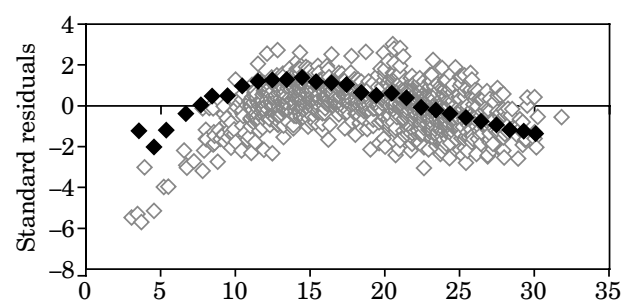

(d)

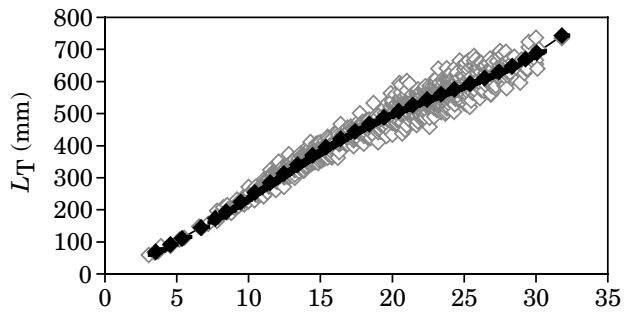

(f)

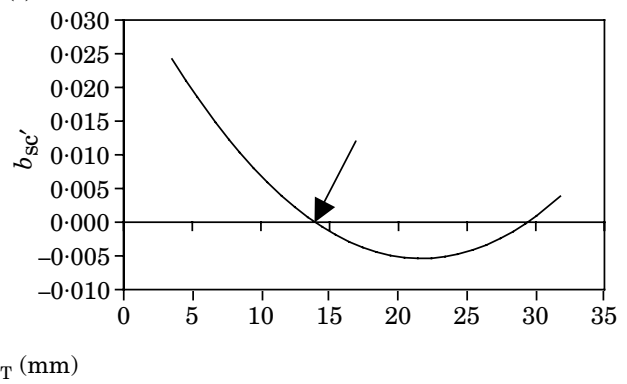

FIG. 3. Total $\left(L_{\mathrm{T}}\right)$ and otolith $\left(L_{\mathrm{OT}}\right)$ lengths of Micropogonias furnieri. $(\diamond$, individual measurements; average values for $1 \mathrm{~mm}$ size class). (a) Relationship between $L_{\mathrm{OT}}$ and $L_{\mathrm{T}}$ estimated from the allometric equation (Huxley, 1924), (b) standardized residuals estimated from allometric equation (Huxley, 1924), (c) distribution of allometry coefficient against $L_{\mathrm{OT}}$ (trend line described by a polynomial function), (d) relationship between $L_{\mathrm{OT}}$ and $L_{\mathrm{T}}$ estimated from the allometric equation with variable allometry coefficient ( $b=$ polynomial), (e) standardized residuals of relationship between $L_{\mathrm{OT}}$ and $L_{\mathrm{T}}$ estimated from allometric equation with variable allometry coefficient $(b=$ polynomial) and (f) first derivative of the polynomial function $\left(\longrightarrow\right.$, the stanzas changing point, $\left.P_{\mathrm{sc}}\right)$. 
allometric coefficient $(b)$ in the Huxley's model (approach 2), which results in

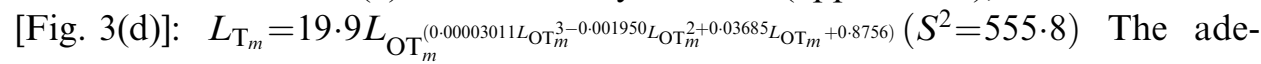
quacy of the new model for relative growth description could be seen through the residuals distribution [Fig. 3(e)].

As a by-product, as described above, the $b_{\text {sc }}$ polynomial function could be used as a first approach to estimate the stanzas changing point of polyphasic allometry (approach 3).

By making $y^{\prime}$ equal to zero in the first derivative of the $b_{\mathrm{sc}}$ function $\left(y^{\prime}=0.00009 x^{2}-0.0039 x+0.03685\right)$ and isolating $x$, the $P_{\text {sc }}$ was estimated as $14.4 \mathrm{~mm}$ [Fig. 3(f)]. Simple power functions were then calculated for each growth stanza (approach 3). Stanza 1 was calculated including otolith average lengths up to $14.4 \mathrm{~mm}$ while stanza 2 was calculated with higher values, resulting in the following equations: stanza $1, L_{\mathrm{T}_{m_{1}}}=14 \cdot 7 L_{\mathrm{OT}_{m}^{1.212}}\left(r^{2}=0.998\right)$ and stanza $2, L_{\mathrm{T}_{m_{2}}}=42 \cdot 1 L_{\mathrm{OT}_{m}^{0.820}}\left(r^{2}=0 \cdot 996\right)$.

These preliminary values of the parameters $a_{1}, b_{1}, a_{2}, b_{2}$ and $P_{\mathrm{sc}}$ were then used as starting values for the adjustment of the mathematical models proposed in approach 3 . Results are summarized in Tables I and II. The proposed models resulted in the following equations for the relationship between the $L_{\mathrm{OT}}$ and $L_{\mathrm{T}}$ in $M$. furnieri: approach 3a (growth with power-equations in stanzas) [Fig. 4(a)], $L_{\mathrm{T}}=(14 \cdot 8$ $\left.L_{\mathrm{OT}}{ }^{1 \cdot 202}\right) F_{\mathrm{w}}+\left(42 \cdot 0 L_{\mathrm{OT}}{ }^{0 \cdot 820}\right)\left(1-F_{\mathrm{w}}\right),\left(S^{2}=562 \cdot 3\right), \quad F_{\mathrm{w}}=\left[1+e^{\left(L_{\mathrm{OT}}-14 \cdot 1\right)}\right]^{-1}$ and approach $3 \mathrm{~b}$ (growth with parameters in stanzas [Fig. 4(b)], $L_{\mathrm{T}}=[14 \cdot 7+$

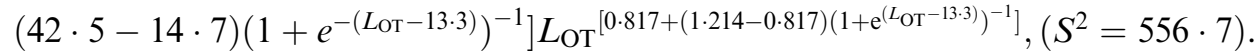

Estimated values, s.E. and $95 \% \mathrm{CI}$ of the parameters are given in Tables I and II and coefficients of determination and residual variances for the Huxley's power function and approach 3 proposed models are presented in Table III. The distribution of standardized residuals resulting from approach $3 \mathrm{a}$ and $3 \mathrm{~b}$ are shown in Fig. 4(c), (d).

TABLE I. Statistical summary of non-linear regression, estimated by SPSS 11.5 software, according to approach $3 \mathrm{a}$ (equations in phases with switch function) (equation 1) where $a_{1}$ and $a_{2}$ are the proportionality coefficients for the first and second growth stanzas, $b_{1}$ and $b_{2}$ are the allometric coefficients for the first and second growth stanzas, $R_{\mathrm{sc}}$ is the stanza changing rate, indicating the speed of changing from stanza 1 to stanza 2 , and $P_{\mathrm{sc}}$ is the value of the variable $x$ that corresponds to the stanza changing point. Model fitted to total length $(y)$ and otolith length $(x)$ of Micropogonias furnieri

\begin{tabular}{lcccc}
\hline & & & \multicolumn{2}{c}{ Asymptotic $95 \%$} \\
\cline { 3 - 5 } & & & CI \\
\cline { 3 - 5 } Parameter & Estimate & Asymptotic & Lower & Upper \\
\hline$a_{1}$ & $14 \cdot 8$ & 1.994 & 10.9 & 18.7 \\
$a_{2}$ & 42.0 & 1.824 & 38.4 & 45.6 \\
$P_{\text {sc }}$ & $14 \cdot 1$ & 1.321 & 11.5 & 16.7 \\
$R_{\text {sc }}$ & 1.0 & 0.527 & -0.033 & 2.032 \\
$b_{1}$ & 1.202 & 0.0574 & 1.090 & 1.315 \\
$b_{2}$ & 0.820 & 0.0137 & 0.794 & 0.848 \\
\hline
\end{tabular}


TABLE II. Statistical summary of non-linear regression, estimated by SPSS 11.5 software, according to the mathematical approach $3 \mathrm{~b}$ (parameters in phases) (equation 2) where $a_{1}$ and $a_{2}$ are the proportionality coefficients for the first and second growth stanzas, $b_{1}$ and $b_{2}$ are the allometric coefficients for the first and second growth stanzas, $R_{\mathrm{sc}}$ is the stanza changing rate, indicating the speed of changing from stanza 1 to stanza 2 and $P_{\text {sc }}$ is the value of the variable $x$ that corresponds to the stanza changing point. Model fitted to total length $(y)$ and otolith length $(x)$ of Micropogonias furnieri

Asymptotic $95 \%$

CI

\begin{tabular}{lcccc} 
& & & \multicolumn{2}{c}{ Cl } \\
\cline { 4 - 5 } Parameter & Estimate & $\begin{array}{c}\text { Asymptotic } \\
\text { S.E. }\end{array}$ & Lower & Upper \\
\hline$a_{1}$ & $14 \cdot 7$ & $2 \cdot 576$ & $9 \cdot 6$ & $19 \cdot 7$ \\
$a_{2}$ & $42 \cdot 5$ & $1 \cdot 810$ & $38 \cdot 9$ & $46 \cdot 0$ \\
$P_{\mathrm{sc}}$ & $13 \cdot 3$ & $1 \cdot 556$ & $10 \cdot 2$ & $16 \cdot 3$ \\
$R_{\mathrm{sc}}$ & $1 \cdot 0$ & $0 \cdot 8011$ & $-0 \cdot 572$ & $2 \cdot 571$ \\
$b_{1}$ & $1 \cdot 214$ & $0 \cdot 0755$ & $1 \cdot 066$ & $1 \cdot 362$ \\
$b_{2}$ & $0 \cdot 817$ & $0 \cdot 0135$ & $0 \cdot 791$ & 0.843 \\
\hline
\end{tabular}

(a)

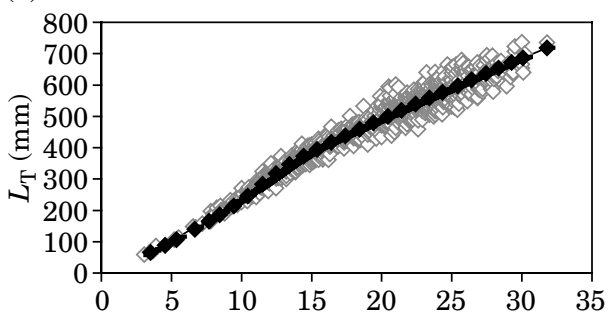

(c)

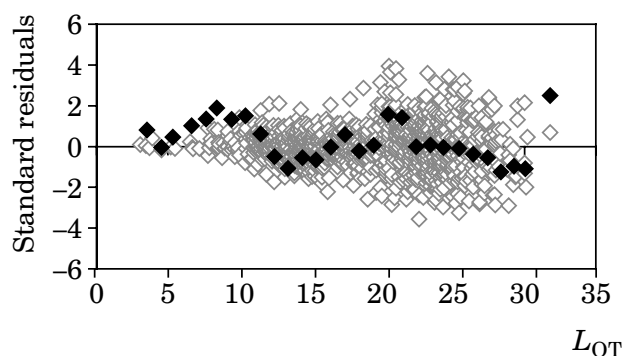

(b)

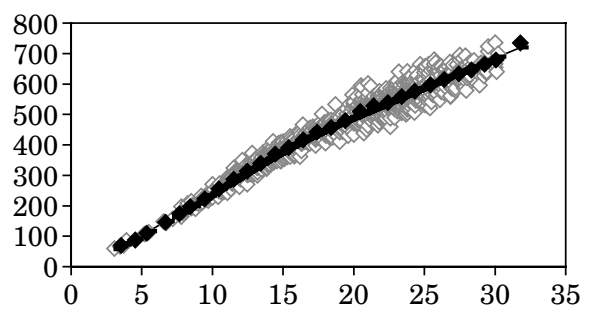

(d)

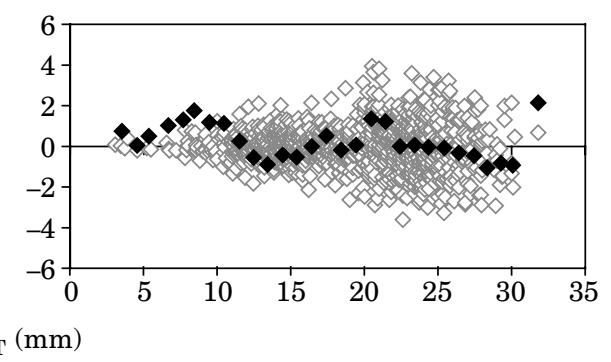

FIG. 4. Total length $\left(L_{\mathrm{T}}\right)$ and otolith length $\left(L_{\mathrm{OT}}\right)$ of Micropogonias furnieri. $(\diamond$, individual measurements; $\diamond$, average values for $1 \mathrm{~mm}$ size class). (a) Relationship between $L_{\mathrm{OT}}$ and $L_{\mathrm{T}}$ estimated following approach $3 \mathrm{a}$ (equations in two stanzas), (b) relationship between $L_{\mathrm{OT}}$ and $L_{\mathrm{T}}$ following approach $3 \mathrm{~b}$ (parameters in two stanzas), (c) standardized residuals of relationship between $L_{\mathrm{OT}}$ and $L_{\mathrm{T}}$ estimated following approach $3 \mathrm{a}$ and (d) standardized residuals of relationship between $L_{\mathrm{OT}}$ and $L_{\mathrm{T}}$ estimated following approach $3 \mathrm{~b}$. 
TABLE III. Statistical summary of residual variances $\left(S^{2}\right)$ and coefficient of determination $\left(r^{2}\right)$, for each of the mathematical models employed. Models fitted to total length $\left(L_{\mathrm{T}}\right)$ and otolith length $\left(L_{\mathrm{OT}}\right)$ of Micropogonias furnieri

\begin{tabular}{llcc}
\hline Mathematical model & General equation & $r^{2}$ & $S^{2}$ \\
\hline Huxley power-function & $L_{\mathrm{T}}=a L_{\mathrm{OT}}^{b}$ & 0.991 & $767 \cdot 4$ \\
Equations in stanzas (equation 1) & $L_{\mathrm{T}}=\left(\right.$ stanza_1 $\left.F_{\mathrm{w}}\right)+$ & 0.960 & $562 \cdot 3$ \\
Parameters in stanzas (equation 2) & $L_{\mathrm{T}}=f(a) L_{\mathrm{OT}} f(b)$ & 0.960 & $556 \cdot 7$ \\
\hline
\end{tabular}

$F_{\mathrm{w}}$, switch function.

\section{DISCUSSION}

Huxley's (1924) allometric model, originally formulated based on the comparison of volumetric measurements, was later expanded to be used for the comparison of linear dimensions. It has been considered as a kind of biological law determining the growth of parts of an organism in relation to each other (Smith, 1980; Lovett \& Felder, 1989). The ease of calculation and interpretation of the allometric coefficient made the model generally useful, but there is some question about the capacity of a power function of the type $y=a x^{b}$ to describe relative growth (Hartnoll, 1982; Lovett \& Felder, 1989; Strauss 1993, Lleonart et al., 2000).

Relationships between calcareous structures and body size in fishes are characterized by variability, generally as a function of external factors such as temperature, salinity and food availability (Casselman, 1990; Swain \& Foote, 1999). Most estimates of fish length by backcalculation are based on hypotheses which assume a proportional growth of the structures under study (Francis, 1990). Growth of calcareous structures in relation to body size, however, is variable, which results in error in the estimates of backcalculated body length (Fukuwaka \& Kaeriyama, 1997). Zivkov (1996) considers that proportional hypotheses do not have a biological meaning, since growth is a complex selfregulating process, which changes continually during ontogeny, so that adequate equations are necessary for a better description of the process.

Recent studies have shown differences between ontogenetic phases in the otolith-body size relationship, through the finding that otoliths grow in increments non-proportional to somatic growth (Reznick et al., 1989; Secor \& Dean, 1989; Hare \& Cowen, 1995). Mosegaard et al. (1988) reported that the somatic and the otolith growth of Salvelinus alpinus (L.) were different at high temperatures, which corroborates the observation that otolith and somatic growth respond differently to environmental factors.

In the case of $M$. furnieri, although changes in the length and mass relationship were not observed (Haimovici \& Velasco, 2000), the curve resulting from the otolith and total length relationship, initially described through a simple powerfunction [Fig. 3(a)], revealed an inadequacy of this model. Although the average $y$ value for each $x$ size class was employed, aiming to reduce the ln-transformation bias, this procedure did not change the general behaviour of the resulting curve, as can be observed in the distribution of the residual values [Fig. 3(b)]. 
The complex ontogenetic pattern of the allometry coefficient [Fig. 3(c)], derived by isolating parameter $b_{\mathrm{sc}}$ and keeping parameter $a$ constant, corroborates the idea that non-constant allometry was present. Nevertheless, was the pattern of the parameter $b_{\mathrm{sc}}$ necessarily too complex to be described by a polynomial function (or any other complex function) as proposed by approach 2? This approach was already proposed, using different equations and general methods, by Jolicoeur (1989) for different data sets concerning several taxonomic groups. Although the proposed model described the data set with enough quality, polyphasic allometry was not tested.

For the present data, polyphasic allometry (approach 3a and 3b), applying just two distinct phases or stanzas in which parameters $a$ and $b$ remained constant, adequately expressed growth as a whole. This simpler and more parsimonious pattern suggests that the complex behaviour of $b$ in approach 2 is a mathematical artefact produced by the transfer of all variability to a single parameter. Nevertheless, as a by-product, approach 2 can be viewed as a new methodological tool for determining the stanza changing points $\left(P_{\mathrm{sc}}\right)$, also called inflection point of polyphasic (log-log) growth models (Sommerton, 1980; Forbes \& Lopez, 1989). This method is neither better nor worse than the previous ones, and is just a new tool for identifying it. Once a method to identify $P_{\mathrm{sc}}$ is chosen, even if identified by eye, the parameter is used only as a starting value in nonlinear fitting routines.

Models $3 \mathrm{a}$ and $3 \mathrm{~b}$ can be used for the description of growth as a whole, since both take into account the existence of allometric variation during ontogeny. Model 3b, however, besides resulting in little residual variance in the data, is more elegant, since it keeps the Huxley's (1924) power-function as a general biological law, in which parameters $a$ and $b$ change during ontogeny. Model 3a just connects two different power-equations by a switch-function and is a mathematical tool to merge different functions (Sommerton, 1980; Forbes \& Lopez, 1989).

The residuals distribution [Figs 3(e) and 4(c), 4(d)] did not show homocedasticity, as is necessary to adjust equations by regular least-squares. This heterocedastic pattern results from regular variability, where absolute variation is larger in bigger animals. Although it could be corrected using average $y$ values for $x$ size classes, as shown in the figures, heterocedasticity did not interfere with the fitting models, as the scatter-plot of residuals were absolutely symmetric above and below the $x$ axis.

Tables I and II show the calculated $P_{\mathrm{sc}}$ at otolith lengths of $c \cdot 14 \cdot 1$ and $13 \cdot 3 \mathrm{~mm}$ (models $3 \mathrm{a}$ and $3 \mathrm{~b}$, respectively). Converting these measurements to the corresponding $L_{\mathrm{T}}$, values of 363 and $337 \mathrm{~mm}$ are obtained. Considering the size at first gonadal maturation of $M$. furnieri estimated for the Brazilian south coast $\left(L_{\mathrm{T} 50}=312 \mathrm{~mm}\right.$; the size at which $100 \%$ of females are mature, $L_{\mathrm{T} 100}=400 \mathrm{~mm}$; Vazzoler, 1971), the $P_{\mathrm{sc}}$ could be related to a change in the growth pattern associated with the reproductive biology of the species. In spite of variations in the first maturation sizes estimated for estuarine regions (190-200 mm; Castello, 1986; Vizziano et al., 2002), the data analysed in the present work were derived from coastal samples. The $P_{\mathrm{sc}}$ is thus a factor, which included in the equation, allows an increase in the level of biological information, besides providing a better description of relative growth. 
The authors thank very much the anonymous referees who greatly contributed for the improvement of the work. Thanks also to $\mathrm{CNPq}$ (Conselho Nacional de Desenvolvimento Científico e Tecnológico) for financial support as a doctoral fellowship to the first author.

\section{References}

Campana, S. W. (1990). How reliable are growth back-calculations based on otoliths? Canadian Journal of Fisheries and Aquatic Sciences 47, 2219-2227.

Casselman, J. M. (1990). Growth and relative size of calcified structures of fish. Transactions of the American Fisheries Society 119, 673-688.

Castello, J. P. (1986). Distribución, crecimiento y maduración sexual de la corvina juvenil (Micropogonias furnieri) en el estuário de la Lagoa dos Patos, Brasil. Physis 44, $21-36$.

Forbes, T. L. \& Lopez G. R. (1989). Determination of critical periods in ontogenetic trajectories. Functional Ecology 3, 625-632.

Francis, R. I. C. C. (1990). Back-calculation of fish length, a critical review. Journal of Fish Biology 36, 883-902.

Fukuwaka, M. \& Kaeriyama, M. (1997). Scale analyses to estimate somatic growth in sockeye salmon, Oncorhynchus nerka. Canadian Journal of Fisheries and Aquatic Sciences 54, 631-636.

Gould, S. J. (1966). Allometry and size in ontogeny and phylogeny. Biological Review 41, 587-640.

Haimovici, M. \& Velasco, G. (2000). Length-weight relationship of marine fishes from Southern Brazil. Naga, The ICLARM Quarterly 23 (Suppl. 1), 19-23.

Hare, J. A. \& Cowen, R. K. (1995). Effect of age, growth rate, and ontogeny on the otolith size - fish size relationship in bluefish, Pomatotus saltatrix, and the implications for back-calculation of size in fish early life history stages. Canadian Journal of Fisheries and Aquatic Sciences 52, 1909-1922.

Hartnoll, R. G. (1978). The determination of relative growth in crustacean. Crustaceana 34 (Suppl. 3), 281-293.

Hartnoll, R. G. (1982). Growth. In The Biology of Crustacea. Embryology, Morphology and Genetics (Abele, L. G., ed.), pp.111-196. New York: Academic Press.

Huxley, J. S. (1924). Constant differential growth-ratios and their significance. Nature 14, 896-897.

Isaac, V. J. (1988). Synopsis of biological data on the whitemouth croaker Micropogonias furnieri (Desmarest, 1823). FAO Fisheries Synopsis $\mathbf{1 5 0 .}$

Jolicoeur, P. (1989). A simplified model for complex bivariate allometry. Journal of Theoretical Biology 140, 41-49.

Le Cren, E. D. (1951). The length-weight relationship and seasonal cycle in gonad weight and condition in the perch (Perca fluviatilis). Journal of Animal Ecology 20, 201-219.

Lleonart, J., Salat, J. \& Torres, G. (2000). Removing allometric effects of body size in morphological analysis. Journal of Theoretical Biology 205, 85-93.

Lovett, D. \& Felder, D. L. (1989). Application of regression techniques to studies of relative growth in crustaceans. Journal of Crustacean Biology 9 (Suppl. 4), 529-539.

Mosegaard, H., Svedang, H. \& Taberman, K. (1988). Uncoupling of somatic and otolith growth rates in Artic char (Salvelinus alpinus) as an effect of differences in temperature response. Canadian Journal of Fisheries and Aquatic Sciences 45, $1514-1524$.

Needham, J. (1950). The form-transformation of the abdomen of the female pea-crab Pinnotheres pisum Leach. Proceedings of the Royal Society B 137, 115-136.

Reznick, D., Lindbeck, E. \& Bryga, H. (1989). Slower growth results in larger otoliths, an experimental test with guppies (Poecilia reticulata). Canadian Journal of Fisheries and Aquatic Sciences 46, 108-112. 
Ricker, W. E. (1975). Computation and interpretation of biological statistics of fish populations. Bulletin of the Fisheries Research Board of Canada 191.

Secor, D. H. \& Dean, J. M. (1989). Somatic growth effects on the otolith-fish size relationship in young pond-reared striped bass, Morone saxatilis. Canadian Journal of Fisheries and Aquatic Sciences 46, 113-121.

Smith, R. J. (1980). Rethinking allometry. Journal of Theoretical Biology 87, 97-111.

Smith, R. J. (1993). Logarithmic transformation bias in allometry. American Journal of Physical Anthropology 90, 215-228.

Sommerton, D. A. (1980). A computer technique for estimating the size at sexual maturity in crabs. Canadian Journal of Fisheries and Aquatic Sciences 37, $1488-1494$.

Strauss, R. E. (1993). The study of allometry since Huxley. In Problems of Relative Growth (Huxley, J. S. ed.), pp. xlvii-lxxv. Baltimore, MD: The John Hopkins University Press.

Swain, D. P. \& Foote, C. J. (1999). Stocks and chameleons: the use of phenotypic variation in stock identification. Fisheries Research 43, 113-128.

Vazzoler, A. E. A. M. (1971). Diversificação fisiológica e morfológica de Micropogonias furnieri (Desmarest, 1823) da costa do Brasil. Boletim do Instituto Oceanográfico 20 (Suppl. 2), 1-70.

Vazzoler, A. E. A. M. (1991). Síntese de conhecimentos sobre a biologia da corvina Micropoginias furnieri (Desmarest, 1823), da costa do Brasil. Atlântica 13, 55-74.

Vizziano, D., Forni, F., Saona, G. \& Norbis, W. (2002). Reproduction of Micropogonias furnieri in a shallow temperate coastal lagoon in the southern Atlantic. Journal of Fish Biology 61 (Suppl. A), 196-206. doi:10.1006/jfbi.2002.2077

Volpedo, A. \& Echeverría, D. D. (2003). Ecomorphological patterns of the sagitta in fish on the continental shelf off Argentine. Fisheries Research 60, 551-560.

Weatherley, A. H. (1972). Growth and Ecology of Fish Populations. London: Academic Press.

White, J. F. \& Gould, S. J. (1965). Interpretation of the coefficient in the allometric equation. American Naturalist 99, 5-18.

Zivkov, M. (1996). Critique of proportional hypothesis and methods for back-calculation of fish growth. Environmental Biology of Fishes 46, 309-320. 